\title{
MENINGKATKAN KEMAMPUAN MEMBACA PEMAHAMAN BERBANTUAN PEMBELAJARAN TEMATIK TERPADU BERNUANSA MODEL INTERACTIVE-COMPENSATORY
}

\author{
Ryan Dwi Puspita ${ }^{1}$ \\ ${ }^{1}$ PGSD STKIP Sebelas April Sumedang \\ 1dwiryan531@gmail.com \\ ${ }^{2}$ Rahman \\ 2Pendidikan Dasar, SPs UPI \\ ${ }^{2}$ rahmanprofupi.upi.edu
}

\begin{abstract}
Based on the preliminary study, it revealed that the 5th grade students in some elementary schools in Bandung Regency had low ability to perform reading comprehension. This can be seen from students' low ability to express explicit meanings, define main idea, search for keywords, retell the contents of the text with their own words, create a concept map, and understand the message of the author. Based on this finding, there is a need to develop instructional devices based on specific learning models to improve reading comprehension. The purpose of this study was to examine the effect of using integrated thematic instructional based on Interactive-Compensatory Model (ICM) to improve reading comprehension among 5th grade students. This study applied quasieksperiment method. This study used sample of 123 students of 5th graders in 2 elementary schools. The results of this study show that the use of instructional based on ICM had significant effect on improving reading comprehension of informational text among grade 5 elementary school students. This was evidenced by the difference of students' reading comprehension ability before and after learning by using thematic and integrated instructional based on ICM.
\end{abstract}

Keywords: Interactive-Compensatory Model, Instructional Integrated and Thematic, Reading Comprehension

\begin{abstract}
ABSTRAK
Hasil observasi menunjukkan siswa kelas 5 di beberapa sekolah dasar di Kabupaten Bandung memiliki kemampuan membaca pemahaman yang lemah. Hal ini ditunjukkan dengan rendahnya kemampuan siswa dalam mengungkapkan makna yang tersurat, menentukan pokok pikiran, mencari kata kunci, menceritakan kembali isi teks dengan kata-kata sendiri, membuat peta konsep, dan memahami pesan penulis. Berdasarkan data ini, maka diperlukan pengembangan perangkat pembelajaran berbasis model pembelajaran khusus untuk meningkatkan kemampuan membaca pemahaman. Tujuan penelitian ini untuk menguji pengaruh penggunaan perangkat pembelajaran tematik terpadu berbasis model Interactive-Compensatory untuk meningkatkan kemampuan
\end{abstract}


membaca pemahaman siswa kelas 5 sekolah dasar. Penelitian ini menggunakan metode eksperimen kuasi. Penelitian ini menggunakan sampel 123 siswa kelas 5 di dua sekolah dasar. Hasil penelitian ini menunjukkan bahwa penggunaan pembelajaran tematik terpadu bernuansa model Interactive-Compensatory berpengaruh signifikan pada peningkatan kemampuan membaca pemahaman teks informasi siswa kelas 5 sekolah dasar. Hal ini dibuktikan dengan adanya perbedaan kemampuan membaca pemahaman siswa pada saat sebelum dan pada saat sesudah pembelajaran dengan menggunakan pembelajaran tematik terpadu bernuansa model Interactive-Compensatory.

Kata Kunci: Membaca Pemahaman, Pembelajaran Tematik Terpadu, Model Interactive-Compensatory.

\section{A. Pendahuluan}

Kemampuan

membaca

pemahaman merupakan kemampuan yang sangat penting dimiliki oleh siswa sekolah dasar. Kemampuan ini diperlukan siswa untuk mempelajari berbagai pelajaran baik secara akademik maupun kehidupan seharihari. Namun fakta di lapangan berbicara bahwa sebagian siswa sekolah dasar terutama kelas 5 di kabupaten Bandung masih ada yang belum memiliki kemampuan membaca pemahaman yang baik. $\mathrm{Hal}$ ini dibuktikan dengan kemampuan mengungkapkan makna yang tersirat masih rendah, siswa belum mampu dalam menemukan ide pokok, kata kunci dengan tepat, siswa belum mampu menyimpulkan isi teks dengan tepat dan siswa belum mampu menguraikan teks dalam bentuk peta konsep. Hal ini didukung oleh hasil temuan PISA (2016) terkait skor rata-rata kemampuan membaca yang diperoleh siswa Indonesia masih di bawah rata-rata negara OECD. Kemampuan pemahaman siswa Indonesia lemah dalam memahami ide paragraf, membaca grafik, memahami hubungan antar fakta, hubungan logika linguistik, dan menemukan ide bacaan. Terkait hasil penelitian Fox (2009), Sahin (2013), Croce (2014), Walters (2014) dalam penelitiannya menemukan sebagian anak-anak sekolah dasar dibeberapa negara lain juga mengalami kesulitan dalam belajar membaca pemahaman yang disebabkan oleh faktor-faktor yang berbeda. Hal ini tentunya ditunjang oleh proses pembelajaran yang kurang efektif. Data ini diperkuat dengan hasil survey kinerja guru sekolah dasar di Jawa Barat hanya mencapai 76,01 yaitu menunjukkan kinerja kurang (Kemdikbud, 2016). Dan hal ini akan menentukan kualitas pembelajaran di kelas khususnya 
sekolah dasar. Kondisi ini menyebabkan lemahnya kinerja guru dalam mengajar yang salah satu indikatornya adalah lemahnya pemahaman dalam memilih model pembelajaran yang tepat.

Kondisi ini menyebabkan keprihatinan peneliti. Dalam hal ini peneliti mencoba menyuguhkan solusi dengan pembelajaran yang efisien dan dikemas dalam kegiatan yang nyaman, yaitu pembelajaran tematik terpadu berbasis model Interactive-Compensatory.

\section{B. Landasan Teori}

Pembelajaran yang secara empirik berhasil memacu percepatan dan meningkatkan kapasitas memori peserta didik (enhance learning and increase long-term memory capabilities of learners) untuk waktu yang panjang adalah perangkat pembelajaran tematik terpadu, karena dalam mempelajari berbagai macam materi pembelajaran disatukan dalam satu tema, sehingga mampu mewadahi dan menyentuh secara terpadu dimensi kognitif, afektif dan psikomotor. pembelajaran tematik terpadu (PTP) atau Integrated Thematic Instruction (ITI) pertama kali dikembangkan pada awal tahun 1970-an. ITI, sebuah model untuk menerapkan lingkungan belajar yang ramah otak bagi siswa dan guru yang menggunakan tema sepanjang tahun untuk mengatur konten dan keterampilan kurikulum. Untuk mengimplementasikan pembelajaran yang kompatibel dengan otak dan menciptakan lingkungan yang akan meningkatkan kinerja anak-anak dan memberikan dasar untuk pengalaman belajar yang sukses (Kovalik\&Olsen, 1994).

Pembelajaran tematik terpadu awalnya dikembangkan untuk siswa yang berbakat dan bertalenta (gifted and talented), cerdas, pada program perluasan belajar, dan yang belajar cepat. Selama ini pembelajaran di sekolah baik pada kelas awal sekolah dasar dan madrasah ibtidaiyah atau kelas-kelas lainnya di sekolah yang sama atau sekolah lanjutan lebih berorientasi pada pembelajaran yang tersegmentasi pada mata pelajaran atau bidang studi. Format mata pelajaran atau bidang studi pada sekolah tersebut mengikuti format keilmuan yang ada, sehingga pengetahuan dan pengalaman murid dalam pembelajaran di sekolah tersegmentasi sesuai segmensegmen ilmu yang dipelajari. 
Akibatnya pengetahuan dan pengalaman murid terpecah-pecah dan tidak utuh sesuai dengan perkembangan anak yang masih memerlukan pengetahuan dan pengalaman yang holistik.

Pembelajaran tematik terpadu sebagai upaya untuk mengintegrasikan perkembangan dan pertumbuhan siswa dan kemampuan pengetahuannya. Pada dasarnya siswa belajar berkat interaksinya dengan lingkungannya baik lingkungan fisik maupun lingkungan sosial. Dari interaksi demikian anak memperoleh pengetahuan dan pengalaman. Ketika siswa berinteraksi dengan lingkungannya ini ia belajar banyak hal, dari subjek matematik, ilmu pengetahuan alam ilmu pengetahuan sosial sampai humaniora. Karena ilmu-ilmu sebagaimana disebutkan di atas ada di masyarakat dan lingkungan sekitar siswa, baik ilmu itu sebagai konsep yang diwacanakan oleh masyarakat maupun praktik dari penerapan ilmuilmu tersebut. Masyarakat dan lingkungan anak sebagai sumber belajar memberikan informasi yang banyak bagi siswa walaupun siswa belum bisa mengelaborasi pengetahuan itu sesuai dengan bidang-bidang ilmu-ilmu tertentu. Tetapi yang diterima siswa adalah satu kesatuan dan keseluruhan tanpa bisa dipecah-pecah. Pembelajaran yang menampilkan ciri menyeluruh dan terintegrasi tidak lain adalah pembelajaran tematik. Kemampuan membaca pemahaman yang harus dimiliki siswa kelas 5 tentunya harus holistik sesuai dengan tujuan pembelajaran tematik terpadu. Namun untuk merealisasikan cita-cita ini penulis menyuguhkan konsep pembelajaran tematik terpadu bernuansa model InteractiveCompensatory.

Model

InteractiveCompensatory merupakan kerangka kerja untuk memahami dan meningkatkan kemampuan guru dalam menciptakan lingkungan pembelajaran yang efisien. Model Interactive-Compensatory mencakup lima komponen utama yaitu: kemampuan kognitif yang terorganisir, basis pengetahuan, strategi, metakognisi, dan motivasi. Kemampuan kognitif mengacu pada kemampuan umum seseorang untuk belajar (kecerdasan). Pengetahuan dasar mengacu pada pengetahuan terorganisir, pengetahuan domain khusus dan pengetahuan umum 
dalam ingatan jangka panjang. ingatan. Strategi mengacu pada prosedur yang memungkinkan peserta didik untuk memecahkan masalah tertentu. Metakognisi mencakup pengetahuan tentang diri sebagai pelajar, dan bagaimana cara mengaturnya (Stanovich, 1984).

Dalam pembelajaran tematik terpadu bernuansa model InteractiveCompensatory untuk meningkatkan kemampuan membaca pemahaman, pemrosesan membaca dilakukan dengan memulai proses membaca dengan pengenalan dan penafsiran terhadap huruf-huruf. Perhatian pembaca diarahkan pada kata-kata dan bagian-bagian kata, sedangkan makna baru timbul dari kumpulan kata-kata yang terbaca. Kegiatan membaca di mulai dengan dasar pengenalan tulisan dan bunyi yang kemudian merekognisi morfem, kata, identifikasi struktur gramatikal, kalimat, lalu teks. Proses rekognisi dari huruf, kata, frasa, kalimat teks dan akhirnya ke makna merupakan urut-urutan dalam mencapai pemahaman. Dengan kata lain proses membaca di mulai dengan melihat teks yang kemudian ditarik ke dalam struktur otak untuk mengidentifikasi dan mencari maknanya. Ketika proses membaca berlangsung, terjadi konsentrasi dua arah pada pikiran pembaca dalam waktu yang bersamaan. Dalam melakukan aktivitas membaca, pembaca secara aktif merespon dan mengungkapkan bunyi tulisan dan bahasa yang digunakan oleh penulis. Selain itu, pembaca dituntut untuk dapat mengungkapkan makna yang terkandung di dalamnya atau makna yang ingin disampaikan oleh penulis melalui teks yang dibacanya.

Membaca merupakan keterampilan memahami teks-teks tertulis dan merupakan kegiatan yang kompleks yang melibatkan persepsi dan berpikir. Pang,et.all., (2000) mengemukakan bahwa "membaca terdiri dari dua proses yang terkait yaitu kata pengakuan dan pemahaman". Kata pengakuan mengacu pada proses memahami simbol bagaimana ditulis sesuai dengan seseorang bahasa lisan. Berdasarkan penjelasan diatas penulis dapat menyimpulkan bahwa membaca dapat diartikan sebagai suatu proses untuk memahami yang tersirat dalam yang tersurat, yakni memahami makna yang terkandung di dalam kata-kata yang tertulis. Makna bacaan tidak terletak pada 
halaman tertulis tetapi berada pada pikiran pembaca. Demikianlah makna itu akan berubah, karena setiap pembaca memiliki pengalaman yang berbeda-beda yang dipergunakan sebagai alat untuk menginterpretasikan kata-kata tersebut (Tompkin \& Hoskisson, 1991). Beberapa ahli menyatakan bahwa proses membaca melibatkan; (1) huruf dan pengenalan kata, (2) pemahaman teks, dan (3) integrasi pemahaman dari teks baru ke pengetahuan atau pemahaman pembaca sendiri untuk menciptakan informasi baru lainnya (Hamra \& Syatriana, 2012). Level kemampuan membaca pemahaman yang ingin dicapai dalam penelitian ini adalah pemahaman literal, pemahaman reorganization, pemahaman inferensial dan pemahaman evaluatif.

\section{Metode Penelitian}

Penelitian ini dilakukan di sekolah dasar yang berada di kabupaten Bandung. Populasi dalam penelitian ini adalah seluruh siswa kelas 5 sekolah dasar dengan ratarata berusia 10-11 tahun. Sampel diambil secara random yaitu empat kelas siswa kelas 5 yang berada di Sekolah Dasar Negeri Sekarwangi, dan Sekolah Dasar Negeri Cingcin 02 . Penelitian ini menggunakan 123 siswa dan 2 guru kelas 5 .

Metode penelitian yang digunakan adalah metode eksperimen kuasi. Desain yang digunakan dalam penelitian ini adalah Nonequivalent Groups PretestPostest Design berbentuk desain kelompok pretest dan postest dengan kelompok kontrol. Dengan 2 kelas sebagai kelas eksperimen $(\mathrm{N}=58)$ dan 2 kelas sebagai kelas kontrol ( $N=65)$.

Data yang diperlukan dalam penelitian ini adalah (1) data analisis kondisi objektivitas pembelajaran tematik terpadu; (2) data kemampuan membaca pemahaman siswa saat ini; (3) data evaluasi efektivitas pembelajaran tematik terpadu bernuansa model InteractiveCompensatory. dalam meningkatkan kemampuan membaca pemahaman. Data analisis kondisi objektivitas pembelajaran tematik terpadu yang saat ini dilaksanakan pada siswa kelas $\mathrm{V}$ sekolah dasar, diperoleh melalui observasi yang dianalisis secara kuantitatif. Data kemampuan membaca siswa saat ini diperoleh melalui observasi. Data efektivitas pembelajaran tematik terpadu 
bernuansa model InteractiveCompensatory yang dikembangkan melalui prates dan pascates yang dianalisis secara kuantitatif dengan uji-t.

\section{Hasil dan Pembahasan}

Tabel 1 di bawah ini menunjukkan hasil uji-t gain kemampuan membaca pemahaman siswa kelas 5 sekolah dasar kelas eksperimen dan kelas kontrol.

Tabel 1 Uji beda gain kemampuan membaca pemahaman siswa kelas 5

\begin{tabular}{|l|l|l|l|l|}
\hline Data & $\boldsymbol{t}_{\text {hitung }}$ & $\boldsymbol{d} \boldsymbol{f}$ & $\boldsymbol{t}_{\text {tabel }}$ & Sig. \\
\hline $\begin{array}{l}\text { Gaineks } \\
\text { _kontrol } \\
1\end{array}$ & 5,260 & 42 & 1 & 0,000 \\
\hline $\begin{array}{l}\text { Gaineks } \\
\text { _kontrol } \\
2\end{array}$ & 6,087 & 78 & 1,9 & 0,000 \\
\hline
\end{tabular}

Berdasarkan tabel 1 terlihat bahwa uji beda rata-rata terhadap gain kemampuan membaca pemahaman kelas eksperimen dan kelas kontrol pada taraf signifikasi 0,05 diperoleh $p$ (sig. $(2$-tailed) $=0,000$. $T$ tabel dapat dicari dengan tabel distribusi $t$ pada taraf kepercayaan 95\% ( $\alpha=5 \%$ ), karena uji t bersifat dua sisi, maka nilai $\alpha / 2=5 \%=0,025$ dan derajat bebas $(\mathrm{df})=\mathrm{n}-2$. Oleh karena $\mathrm{p}<0,005$, maka Hi diterima dan Ho ditolak, atau kedua rata-rata terdapat perbedaan. Pengambilan keputusan juga dapat dilakukan dengan cara membandingkan nilai t hitung dengan $t$ tabel, dengan ketentuan sebagai berikut :

- Jika $t_{\text {hitung }}<t_{\text {tabel }}$, maka Ho diterima dan Hi ditolak.

- Jika $t_{\text {hitung }}>t_{\text {tabel }}$, maka Ho ditolak dan Hi diterima.

$t_{\text {hitung }}>t_{\text {tabel }}$ atau didalam daerah penolakan Ho maka diputuskan bahwa Ho ditolak dan $\mathrm{Hi}$ diterima. Dengan demikian dapat disimpulkan bahwa terdapat perbedaan yang signifikan antara rata-rata skor gain kelas eksperimen dan kelas kontrol dalam kemampuan membaca pemahaman siswa pada taraf kepercayaan $95 \%$.

Penelitian ini menunjukkan adanya peningkatan kemampuan membaca pemahaman teks informasi siswa kelas 5 sekolah dasar. Hasil penerapan pembelajaran tematik terpadu bernuansa model InteractiveCompensatory ini sangat variatif. Kategori kemampuan membaca pemahaman dari tiap sekolah memiliki nilai yang berbeda-beda. Kemudahan akses informasi sangat 
mempengaruhi

kemampuan

membaca pemahaman siswa sekolah dasar. Akses informasi disini tidak hanya informasi dari media elektronik ataupun akses internet tetapi ketersediaan buku bacaan untuk siswa merupakan akses yang sangat dibutuhkan oleh siswa sekolah dasar. Hasil analisis menunjukkan bahwa hampir $80 \%$ siswa sudah mampu mengingat makna yang tersurat. Contohnya yang pertama adalah siswa mampu mengenali makna yang tersurat, menentukan ide pokok, kata kunci, menyimpulkan teks dan menguraikan teks dalam bentuk peta konsep yaitu siswa mampu menyebutkan fungsi organ tubuh manusia secara lisan dan tertulis, siswa mampu menyebutkan proses daur air secara lisan dan tertulis. Siswa juga sudah mampu mengidentifikasi gambar organ tubuh manusia dan mengidentifikasi gambar daur ulang air.

Kemampuan siswa dalam penelitian ini sudah mencapai pada level dua membaca pemahaman yaitu kemampuan evaluatif. Namun siswa masih mengalami kesulitan dalam hal memahami makna tersirat dalam teks yang dibaca. Contohnya adalah siswa kesulitan dalam mengambil manfaat yang penting dari informasi penting yang ada dalam teks. Hal ini dialami siswa karena siswa belum terbiasa ditugaskan untuk menentukan makna yang tersirat dalam teks yang dibaca. Dalam hal ini adalah kurang tepatnya desain tugas yang diberikan guru pada waktu pembelajaran. Desain tugas dengan pengalaman yang menyenangkan diharapkan siswa mampu menggunakan pengalaman dan pengetahuan yang dimilikinya untuk dipergunakan dalam kehidupannya dan berbagi pengetahuan dengan orang lain. Selaras penjelasan Lynn Chu, et.al (2016) yang memberikan kontribusi pada pemahaman kita tentang pengalaman belajar yang menyenangkan bagi anak dalam kegiatan pembelajaran terpadu di kelas sekolah dasar. Anak menunjukkan kesenangan ketika melakukan eksperimen karena keterlibatan merupakan hal utama yang menjadikan proses pembelajaran menjadi bermakna. Dalam pembelajaran terpadu ini, anak diberikan kesempatan untuk mengajukan pertanyaan, mengamati, berdiskusi, mengolah data, mempresentasikan. Pembelajaran 
Pendas : Jurnal IImiah Pendidikan Dasar, ISSN Cetak : 2477-2143 ISSN Online : 2548-6950 Volume II Nomor 2, Desember 2017

terpadu ini memungkinkan berbagai jenis pengetahuan dapat diperoleh. Hal ini membuktikan bahwa pembelajaran menggunakan tema untuk pembelajaran, anak dapat menemukan kesenangan belajar secara formal.

Pembelajaran tematik terpadu bernuansa model InteractiveCompensatory ini menawarkan pembelajaran menjadi aktivitas pembelajaran menjadi penuh makna bagi siswa, baik aktivitas formal maupun informal, meliputi pembelajaran inquiry secara aktif hingga penyerapan pengetahuan dan fakta pasif, dengan memberdayakan pengetahuan dan pengalaman siswa untuk membantunya dan memahami dunia kehidupannya. Cara pengemasan pengalaman belajar yang dirancang oleh guru akan sangat berpengaruh terhadap kebermaknaan pengalaman siswa dan menjadikan proses pembelajaran menjadi lebih efektif dan menarik. Berdasarkan hasil angket, umumnya siswa tidak disediakan buku penunjang juga di rumahnya masingmasing. Mereka hanya mendengarkan dongeng dari ayah atau kakeknya. Ketidaktersediaan buku-buku pelajaran dan buku penunjang yang terkait sangat mempengaruhi kemampuan membaca pemahaman siswa kelas 5 sekolah dasar. Masalah lainnya adalah kurangnya motivasi membaca siswa, menemukan bahwa 40 persen masalah pembaca yang buruk mengacu pada kurangnya motivasi membaca.

(Maftoon\&Tasnimi,2013;Kamg ar,et.al.,2016) menyarankan guru harus memiliki lebih banyak strategi dalam mengajarkan keterampilan membaca untuk meningkatkan motivasi siswa dan mereka melihat guru sebagai model. Agar siswa mampu belajar sendiri, dan mengembangkan otonomi mereka. Selain faktor guru yang mempengaruhi, faktor lingkungan belajar juga sangat mempengaruhi seperti penyediaan media pembelajaran dan lembar belajar yang menyenangkan.

Peneliti menemukan ada beberapa siswa yang dengan mudahnya memahami teks informasi. Dan peneliti melakukan wawancara kepada siswa tersebut. Hasilnya, beberapa siswa yang dengan mudah memahami teks informasi salah satunya senang belajar melalui latihan-latihan yang dilakukan sendiri 
tanpa bantuan orang lain. Ada juga siswa yang sudah terbiasa membaca teks informasi di koran ataupun di buku-buku bacaan milik ayahnya. Sehingga siswa-siswa tersebut menjadi aktif ketika pembelajaran di kelas. Ada beberapa siswa yang sudah mampu mengkritisi bahan ajar yang peneliti gunakan. Mereka memberi masukan agar kata-kata dalam bahan ajar tidak terlalu sulit untuk dipahami.

Pada salah satu sekolah ditemukan siswa yang sudah memiliki pemahaman apresiasi yaitu siswa tersebut sudah mampu membedakan genre, mengartikulasikan tanggapan dia sendiri terhadap maksud penulis. Hal ini terjadi karena siswa tersebut sering membaca baik buku pelajaran ataupun buku sastra. Siswa tersebut tidak mengalami kesulitan pada saat memahami teks informasi, karena didukung oleh pengetahuan awal yang sudah mumpuni. Karena kemampuan pembaca untuk memahami bahan bacaan tergantung pada bagaimana mereka memandang teks. Persepsi ini dapat didasarkan pada pengalaman atau pertemuan sebelumnya dengan kata atau gagasan Mirasol, (2015). Hal ini diperkuat dengan penelitian Yusuf
(2015) yang menjelaskan bahwa aktivitas interaktif akan bermanfaat mengubah makna dengan melibatkan siswa dalam langkah-langkah strategis yang bertujuan. Kegiatan interaktif adalah kegiatan siswa yang menuntut tingkat partisipasi siswa yang tinggi dan berbagai bentuk kegiatan kelompok mulai dari diskusi sampai menceritakan kembali. Guru membimbing siswa untuk melakukan tugas belajar yang berbeda pada berbagai tingkat interaksi. Pada intinya, siswa belajar tentang proses mental yang terlibat dalam mengaktifkan gagasan dan membuat koneksi antara ide-ide baru dan diketahui. Strategi ini membuat siswa sadar bahwa tiga jenis makna berbeda dapat terjadi yang dibangun saat membaca yaitu literal, inferensial dan personal. Mereka mengembangkan pemahaman bahwa pengetahun pembaca sebelumnya memainkan peran penting dalam membangun makna dan beberapa makna ada di sekitar teks.

\section{E. Kesimpulan}

Simpulan dari penelitian ini adalah pembelajaran tematik terpadu bernuansa model InteractiveCompensatory untuk meningkatkan kemampuan membaca pemahaman 
teks informasi siswa kelas 5 sekolah dasar keberhasilannya ditentukan oleh beberapa faktor yaitu intervensi guru dalam membangun pemahaman siswa terhadap teks, pengetahuan awal siswa terkait dengan tema, ketersediaan buku-buku penunjang terkait dengan tema, tingkat kesukaran teks informasi yang dibaca oleh siswa. Harus ada desain tugas yang mampu mengaktifkan pengetahuan awal siswa, menjadikan siswa mampu berpikir kritis, dan membantu mempermudah cara belajar siswa untuk memahami teks.

\section{DAFTAR PUSTAKA}

Croce, Anne Keri. (2014). Assessment of Burmese Refugee Students' Meaning Making of Scientific Informational Texts. Journal of Early Childhood Literacy, Vol. 14(3) 389-424.

Fox, Emily. (2009). The Role of Reader Characteristics in Processing and Learning From Informational Text. Review of Educational Research Spring 2009, Vol. 79, No. 1, pp. 197261.

Hamra, Ariffudin, Syatriana, Eny.
Teaching for University EFL Students: Need Analysis and Model Design. English Language Teaching, Vol.5, No.10, 1-11.

Kamgar, Narges.,Jadidi, Esmaeil. (2016). Exploring The Relationship of Irania EFL Laerners' Critical Thinking ans Self Regulation With Their Reading Comprehension Ability. ScienceDirect. 776783.

Kementrian Pendidikan dan Kebudayaan. (2016). Sumber Daya Manusia Pendidikan Dasar dan Menengah. Jakarta: Pusat Data dan Statistik Pendidikan dan Kebudayaan. Kovalik, S., K. Olsen. (1994). ITI: The Model. Integrated Thematic Instruction. 3rd ed. Kent, Wash.: Books for Educators.

Lynn Chu, Sharon, et.al. (2016). Fun In Making: Understanding The Experience Of Fun And Learning Through CurriculumBased Making In The Elementary School Classroom. ScienceDirect. S18759521(2016)30028-3.

(2012). A Model of Reading 
Mirasol, Rosalyn Gunobgunob. (2015). The Relative Effect of Glossing Instruction College Students' Reading

Comprehension.

ScienceDirect. 208, 82-90.

Pang, S. Elizabeth,et.all. (2003). Teaching Reading. UNESCO.

PISA. (2016) Science Competencies for Tomorrow's World. ISBN: 9789264040007.

Sahin, Ayfer. (2013). The Effect of Text Types on Reading Comprehension. Mevlana International Journal of Education (MIJE). Vol. 3(2), pp. 57-67, 1.

Stanovich, Keith E. (1984). The Interactive-Compensatory

Model of Reading $A$ Confluence of Developmental Psycology. Volume.5, Isuue 3. Walters, Braker, Barbara A. (2014). Informational Text and the Common Core: A Content Analysis of Three Basal Reading Programs. SAGE. 18.

Yusuf, Hanna Onyi. (2015) Interactive Activities ans Its Impact on Students' Performance in Reading Comprehension In Senior Secondary Schools In
Kaduna

Nigeria. 